NBER WORKING PAPER SERIES

FEDERAL RESERVE POLICY:

CAUSE AND EFFECT

Matthew D. Shapiro

Working Paper No. 4342

NATIONAL BUREAU OF ECONOMIC RESEARCH 1050 Massachusetts Avenue

Cambridge, MA 02138

April 1993

The author is grateful to Robert Barsky, Charles Fleischman, Lung-Fei Lee, Bennett McCallum, N. Gregory Mankiw, David Romer, anonymous reviewers, and the conference participants for helpful comments on preliminary drafts. Carlos Quintanilla provided able research assistance. This research was undertaken while he was an Alfred P. Sloan fellow. This paper is part of NBER's research programs in Economic Fluctuations and Monetary Economics. Any opinions expressed are those of the author and not those of the National Bureau of Economic Research. 


\section{FEDERAL RESERVE POLICY: \\ CAUSE AND EFFECT}

\section{ABSTRACT}

Romer and Romer $(1989,1990,1992)$ identify dates where the Federal Reserve appears to have shifted its policy towards reducing the rate of inflation. This paper examines the economic context that drives this decision. It finds that the Fed appears to weigh the outlook for unemployment as well as that for inflation in making its decision about disinflation.

Previous work has not examined the course of inflation over the disinflations. This paper finds responses of the inflation rate to the "disinflations" only in a specification where the effects of the policy are presumed to be permanent. Moreover, the Volcker disinflation is found to be the only "disinflation" to reduce inflation permanently. The disinflation after the 1973 OPEC price increases was effective, but only temporarily. Other disinflations had negligible impacts on the rate of inflation over all horizons.

Variables measuring the expected present discounted values of unemployment and inflation are constructed. These variables are used in a discrete-choice model to explain the Fed's decision to disinflate. This model does a fairly good job of explaining the Fed's decisions. Both inflation and unemployment drive the Fed's decision. For some episodes, notably in the 1970 's, inflation is the main variable driving the decision. In the 1969 and 1988 episodes, unemployment matters more.

\section{Matthew D. Shapiro}

Department of Economics

University of Michigan

Ann Arbor, MI 48109-1220

Tel: (313) 764-5419

and NBER 
The Federal Reserve periodically makes decisions to reduce the rate of inflation. Romer and Romer (1989, also 1990), in a recent and influential study, identify six dates since World War II when Federal Reserve policy became explicitly disinflationary. They have recently added a seventh date (Romer and Romer, 1992). ${ }^{1}$ They find evidence of the effectiveness of Fed policy consistent with the predictions of the neo-Keynesian model. The disinflations are followed by periods of substantial output and employment loss.

Romer and Romer, in both their historical and econometric methodology, treat the changes in Fed policy as exogenous events.

In their examination of the Federal Open Market Committee [FOMC] minutes, they look explicitly for innovations in Fed policy concerning the steady-state rate of inflation. They deliberately avoid an examination of economic conditions in dating the Fed

'The dates identified in Romer and Romer (1989) are 1947:10, 1955:09, 1968:12, 1974:04, 1978:08, and 1979:10. Romer and Romer (1992) adds 1988:12. The preliminary research for this paper was carried out before the Romers identified this latest date. The estimates in this paper, however, incorporate the new Romer date. 
decisions. In their econometric work, they treat these changes in Fed policy as observed, exogenous impulses that determine the course of real economic activity and inflation. Hence, the impact of the policy shifts is estimated by ordinary least squares. The dynamic multipliers implied by these estimates are thus taken as the impact per se of the policy.

Romer and Romer's perspective of treating policy variables as exogenous is part of a long tradition. Most studies of the effectiveness of monetary policy use time-series indicators of monetary policy such as growth rates of money stocks or interest rates as predictors of aggregate economic outcomes. By ignoring the feedback of the economy to policy, these studies treat policy changes as random shocks.

But, of course, decisions by the FOMC to change policy take place with explicit consideration of economic conditions. A decision to disinflate is meaningful only if there is a precondition of existing high inflation, either actual or expected. Therefore, there must be feedback from the economy to policy-making. Even if the Fed's actions can be regarded as predetermined, they are 
certainly not strictly exogenous. The FOMC is reacting to the economy and hoping to affect it.

The first part of this paper examines the effects of the Fed's decision to disinflate. That these decisions are followed by substantial declines in real activity is well documented in the Romers' papers. Previous work does not, however, examine the effect on inflation of the disinflationary shifts in policy. Since disinflation is the Fed's explicit objective, I develop quantitative estimates of the disinflationary effect of the policy change in order to study systematically the decision to undertake it.

The second part of the paper uses what is learned about the effects of a decision to disinflate to examine its determinants. It constructs measures of variables driving the Fed's decision to disinflate. It then develops a discrete-choice model that shows how these variables explain the Fed's actions.

\section{1. $\quad \underline{E F F C T S}$}

In discussions of cause and effect, cause usually comes before effect. Yet, at least insofar as the empirical work for this paper is concerned, the effects of disinflation need to be studied 
first. Presumably, the Fed has an estimate of the impact of its policy before undertaking it. But in order to model that decision, I must first construct similar estimates of the costs and benefits of the decision.

Surprisingly, the literature has not addressed the very basic question, what is the consequence for inflation of a decision by the Fed to disinflate? Empirical work by Romer and Romer documents the costs of a decision to disinflate. They show forecasts of production and unemployment responding to these Federal Reserve Policy shifts. Taken for granted is that the disinflationary episodes have a favorable impact on inflation. For the empirical modelling of the decision to disinflate, I need, however, a quantitative estimate of the benefits as well as the costs. Therefore, I will examine in some detail the anti-inflation consequences of the disinflations.

\subsection{Specification of the inflation process}

The variables I consider are inflation measured by the consumer price index, the civilian unemployment rate, and the 
Romer dummies. ${ }^{2}$ The goal of this section is to develop forecasts of inflation and unemployment conditional on a policy change. These forecasts will then be used as an input into the model of Fed decisions in Section 2.

Since the aim of this section is to develop forecasts, it relies on simple time-series models of inflation and unemployment conditional on their own lags and lags of the Romer dummies. I present both univariate estimates and bivariate estimates, where lags of the unemployment rate appear in the inflation equation and vice versa.

Figures 1 and 2 present the basic data. The unemployment rate has a clear and well-known upward trend for most of the

${ }^{2}$ The data are quarterly. The monthly Romer dummies are converted to quarterly as dummies for quarters during which a Romer date occurs. The inflation rate is measured as the threemonth percent change (log-differences at annual rate) for the quarter. The unemployment rate is the average for the quarter. The sample period is from 1953:1 to 1992:4 (see below for discussion of sample period). The sample period refers to range of the dependent variables in any equation estimated, so in those involving lags, the appropriate pre-sample data are used. 
sample. In the econometric work that follows, the unemployment rate is detrended with a linear trend. The trend arises because of labor-market phenomena not closely linked to short-run Fed policy, so abstracting from the trend seems appropriate.

Specification of the inflation process is more problematic. As a matter of theory, it is desirable to allow for persistent impacts of the decision to disinflate on the level of inflation. Only finite lags of the Romer dates are entered into the equations. Hence, in an equation that has the level of inflation as the left-hand-side variable, a policy change will have only temporary, although possibly very persistent, impacts on the inflation rate. In a specification where the difference of inflation is the dependent variable, they will in general have permanent effects, although the long-run effect could be small.

Of course, the empirical persistence of the inflation process must be considered. Previous work has found post-World War II inflation, in contrast with earlier samples [see Barsky (1987)], to be very persistent. The persistence of inflation is, however, very sensitive to the sample period. As we get more and more observations after the Volcker disinflation, inflation looks more 
mean-reverting. But even more important is how the earlier years of the post-War period are treated. The period 1947-1952 has dramatic swings in inflation associated with the post-World War II and Korean War business cycles and with price controls and their aftermath. Consequently, estimates in this paper are carried out over the period beginning in 1953. No claim is made that the results are robust to inclusion of the 1947-1952 period. Quite the contrary, the results are very sensitive to inclusion of this period. Since there are strong a priori grounds for expecting the early period to be different from the later, including it in the sample would not shed much light on behavior of the economy during the bulk of the post-war period.

Table 1 documents this sensitivity of the inflation process to the sample period. It reports the regression results of the change of inflation on seven of its own lags and the lagged level. The table reports the implied largest autoregressive root of the level of inflation and its $\mathrm{t}$-statistic for the null that it is unity. Both these statistics have Dickey-Fuller (1981) distributions. The first three rows report results starting in 1947 . These document the instability of the inflation process in the early period. For both the 1947 - 
1992 and $1947-1979$ periods, inflation is estimated to be rapidly mean-reverting (largest roots of 0.68 or 0.66 ). But the next rows show that much of the mean-reversion over the post-war period arises from the 1947-1952 period. This period had very unpersistent inflation (root of 0.19). On account of this very different behavior, together with the Korean War price controls, I start the sample in 1953.

In the 1953-1992 period, inflation is just on the boundary between accepting and rejecting the unit-root hypothesis. The largest autoregressive root is 0.84 ; the Dickey-Fuller t-statistic of 2.97 is marginal at conventional significance levels. The last row shows that even in the 1953-1992 period, there are important changes in the persistence of unemployment. In the 1953-1979 period, the root is much closer to unity and the test-statistic is in the region of non-rejection. Inflation looked very persistent over this period. Since the Volcker disinflation of the 1980's, it looks more mean-reverting. As I will argue later in this section, the Volcker disinflation is a singular event, so it is hard to predict its lasting consequences for the process of inflation. 
In light of the sensitivity of the inflation process to specification and sample period, many of the results of this paper will be presented for specifications using both the level and difference of inflation. It is already clear from Table 1 that certain results, those concerning inflation, will be sensitive to the specification of its process. But other results, in particular those relating to unemployment, are not.

\subsection{Results: Effects of Policy Changes}

Let $\pi_{\mathrm{t}}$ be the inflation rate and $u_{\mathrm{t}}$ be the unemployment rate. The equations to estimate what happens after a Romer date are specified as follows

$$
\begin{gathered}
\Delta \pi_{t}=\beta_{\pi} \pi_{t-1}+A_{\pi \pi}(L) \Delta \pi_{t-1}+A_{m u}(L) u_{t-1}+D_{\pi}(L) R_{t-1}+\epsilon_{1 t} \\
u_{t}=\beta_{u} \pi_{t-1}+A_{u m}(L) \Delta \pi_{t-1}+A_{u u}(L) u_{t-1}+D_{u}(L) R_{t-1}+\epsilon_{2 t}
\end{gathered}
$$


where $\Delta \pi_{\mathrm{t}}$ is the change of the inflation rate, $R_{t}$ is the dummy variable that is one on a Romer date and zero otherwise, and $A(L)$ and $D(L)$ are polynomials in the lag operator. The $A(L)$ polynomials are eighth-order and unrestricted. ${ }^{3}$ The $D(L)$ polynomials, which capture the impact of the Romer dates, include lags one through sixteen and are estimated as fourth-order polynomially-distributed lags with the far endpoint restricted to zero. ${ }^{4}$ When estimated as unrestricted, the lag distributions are noisier, but have basically the same dynamics.

The coefficients $\beta$ are constrained to be zero in the nonstationary specification of inflation and freely estimated when inflation is allowed to be stationary. Including the lagged level of inflation.in the equations is equivalent to respecifying the

${ }^{3}$ The $A_{u \pi}(L)$ polynomial also is such that the current value $\pi_{t}$ of the inflation rate is included in the equation for unemployment. This is merely a normalization to make the error terms uncorrelated. It is equivalent to using the triangularization popular in the literature on vector autoregressions.

${ }^{4}$ Sixteen lags is long enough so that the endpoint restriction is not strongly binding. 
equations in terms of the level of inflation. This normalization facilitates comparison of the estimated coefficients across the specifications of the inflation process. ${ }^{5}$

\subsubsection{Univariate Estimates}

The results for the univariate estimates are presented in Tables 2 and 3 and Figures $2 a$ and $3 a$. Consider first the estimates for unemployment (the same in both tables). ${ }^{6}$ Unemployment has the hump-shaped dynamics that is typical of real aggregates. After a shock to unemployment, it continues in the same direction for several quarters before slowly reverting to trend. The Romer dates increase unemployment gradually. Figure 2 a shows the convolution of the Romer dates and the own-lags of unemployment. Following a Romer date, unemployment gradually

${ }^{5}$ To make the nonstationary and stationary models have the same degrees of freedom, when inflation is allowed to be stationary by including the lagged level $\pi_{t-1}$, I include only seven lags in the polynomials in $\Delta \pi_{t \cdot 1}$.

${ }^{6}$ Recall that here and throughout that $u_{t}$ is the deviation of unemployment from a linear trend. 
increases to a peak level of 1.73 in the fifteenth quarter after the shocks and then slowly reverts to trend. As subsequent figures show, these dynamics are essentially invariant to the specification of the inflation rate and to whether a univariate or bivariate system is estimated. They replicate the findings presented by Romer and Romer (1989). The tables give the F-statistic for the null hypothesis that the all of the coefficients of the Romer dates are zero. ${ }^{7}$ For unemployment, this hypothesis is rejected at the 0.03 level.

The constant of the unemployment rate equation has an interesting interpretation. Since the variable $u_{t}$ is zero mean, it would be zero but for the inclusion of the dummies for disinflation. The estimated coefficient indicates that the Romer dates increase the average unemployment rate by about one-tenth of one percentage point.

Now consider the estimates of the inflation process.

${ }^{7}$ Because the lags of the Romer are estimated as a fourth-order polynomial with a far endpoint constraint, the hypothesis has only three restrictions. 
Even conditioning on the Romer dates, inflation is persistent. The coefficient of the lagged level of inflation in Table 3 is not significantly different from zero. Hence, inclusion of the Romer dummies does not affect the unit-roots tests reported in Table 1. Inflation is, however, less persistent than a random walk (see the negative coefficients of the lagged $\Delta \pi$ ). The coefficients of the lagged Romer dates have similar patterns in Table 2 and Table 3. Following a Romer date, inflation continues to accelerate for two quarters and then decelerates. The joint test that the coefficients Romer dates are all zero rejects for the nonstationary, but not for the stationary specification.

The dynamic response of inflation to the Romer dates is again easiest to see in the figures. Figure 2a gives the response for the univariate, inflation-nonstationary model; Figure $3 a$ gives it for the univariate, inflation-stationary model. Both figures report the response of the level of inflation to a Romer date. For the nonstationary specification in Figure 2a, inflation continues to accelerate for several quarters. It then decelerates until it levels off after about four years at a level five percentage points lower than where it began. This change is economically significant. The 
standard error of the inflation equation is about 2 percentage points, so the reduction is $2-1 / 2$ times the innovation's standard error. But as will be shown in Section 1.2.3, the magnitude of the change is attributable largely to the Volcker disinflation.

The pattern for the stationary-inflation model in Figure 3a is similar, although the magnitudes are not. The maximum reduction in inflation is only about 3 percentage points, and, of course, it is temporary. Moreover, recall that the coefficients of the Romer dates are not significantly different from zero in the estimates reported in Table 3, so the projected disinflation is not statistically significant.

\subsubsection{Multivariate estimates}

Tables 4 and 5 and Figures $2 \mathrm{~b}$ and $3 \mathrm{~b}$ report the results of estimating the multivariate model where the change in inflation and the level of unemployment are regressed on their own lags and 
lags of the unemployment rate..$^{8}$ Both nonstationary- and stationary-inflation models are again estimated.

Figures $2 b$ and $3 b$ report the total responses to a Romer date. That is, for inflation, the changes in lagged unemployment are taken into account and vice versa. The estimated response of unemployment and inflation to disinflations are very similar to the corresponding estimates for the univariate models in the (a) panels of the figures. The similarity of the univariate and multivariate estimates of the response of inflation and unemployment to a disinflation disguises interesting differences that are revealed in the estimates of the equations reported in the tables. In the unemployment equation, the coefficients of the Romer dates do not change much between Tables 2 and 4 . Including the lagged changes in inflation only slightly attenuates the coefficients of the Romer dates in the unemployment equation in Table 4. They remain statistically significant, although at the 0.06 rather than 0.03 level.

${ }^{8}$ Also, the current change in inflation is included in the unemployment rate regression to normalize the residuals to be uncorrelated. 
On the other hand, when lags of unemployment are included in the equation for the change in inflation in Table 4, the coefficients of the Romer dates get considerably smaller than those in the univariate model in Table 2. Moreover, the coefficients of the Romer dates in the inflation equation in Table 4 are jointly statistically insignificant ( $\mathrm{p}$-value of the F-statistic is 0.51 ). Hence, the impact on inflation of the Romer dates in the multivariate system operates indirectly through the impact of lagged unemployment rather than directly in the inflation equation. Since the estimated equations are reduced form, they need to be interpreted with caution. Yet, the absence of an independent impact of the Romer dates on inflation does suggest that disinflations operate through the Phillips curve rather than by independent shifts in the inflationary regime.

Including the lagged unemployment rates in the equation for inflation in the stationary specification has a similar effect (compare Tables 3 and 5). The coefficients of the Romer dates in the inflation equation in Table 5 are substantially smaller than those in Table 3. But they are insignificant in both the univariate 
and multivariate equations, so the difference in the magnitudes of the coefficient estimates should not be overinterpreted.

\subsubsection{Disinflations Episode-by-Episode}

In the inflation-nonstationary specification, the estimates reported in this section imply that the disinflations have, on average, a substantial, permanent effect on the inflation rate. These come at a cost of high unemployment for a period of years. But as Feldstein (1979) points out, a permanent gain from lower inflation could well outweigh the temporary output loss.

The estimates based on the regressions for the whole period have important limitations. Specifically, they impose that the magnitude of the disinflation is the same across episodes. ${ }^{9}$ It could well be that certain episodes represented much more substantial contractions than others. In this subsection, I present evidence that reveals what success the Fed had in reducing the rate of inflation following each Romer date.

${ }^{9}$ I am grateful to Saul Hymans and Phil Howrey for stressing this issue to me. 
To examine the impact of the disinflations episodically, I use the following simple, nonparametric procedure. I estimate a univariate autoregression of the change of inflation over the entire sample. The equation includes a constant and eight lags of $\Delta \pi_{v}$, but no Romer dummies. Figure 4 shows graphs of the cumulative forecast error for the level of inflation from the quarter before each Romer date. ${ }^{10}$ The solid lines are the forecast errors, the dashed lines are the one-standard-deviation error bands. For example, in Figure 4c, inflation is almost 8 percent lower in 1976:1, eight quarters after the Romer date, than it was forecast to be in 1974:1, the quarter before the decision to disinflate.

Figure 4 shows that, except for the October 1979 Volcker disinflation, none of the decisions to disinflate had a permanent impact on the level of inflation. (Figure $4 \mathrm{~d}$ credits the August 1978 disinflation with a long-run impact, but the forecast errors do not turn negative until after the October 1979 date.) Forecast errors after the September 1955 (Figure 4a) episode were large

${ }^{10}$ Romer and Romer (1989, Figure 3) provide an analogous figure for the unemployment rate. 
and positive. After the December 1968 (Figure 4b) episode, the errors were small--first positive and then negative. In the disinflation following the first OPEC price increase (Figure 4c), there were persistent and large negative forecast errors. Over the two year horizon, there were substantial reductions in the realized rate of inflation relative to expectation, but these begin to dissipate in 1976. By early 1978 (note that this date is before the second OPEC oil price increase), inflation is close to its pre-disinflation expected value. Hence, if this episode is to be counted as a success, there must be some offsetting failure subsequent to it. Moreover, the failure of the OPEC I disinflation to have lasting benefits cannot be blamed on OPEC II. Any success had dissipated before the second oil shock.

Figure 4d tells the story of the August 1978 disinflation. It totally failed to affect the forecast errors. They remain positive in the first six quarters. The subsequent reductions in inflation occurred after the 1979 episode.

The October 1979 episode is the outstanding success. It heralded a sustained, large reduction in the rate of inflation. Five years after it, the rate of inflation was 8.5 percentage points lower 
than would have been forecast in the quarter before the decision to disinflate. From Figure 4, it is clear that this data point is virtually alone in driving the estimates of the long-run effect of the Romer dummies on inflation presented in the previous subsections.

Finally, Figure $4 \mathrm{f}$ reports the effect of the most recent episode. After bouncing around for several years, the forecast error does settle down below zero, but it is well within the onestandard-deviation band.

\subsubsection{Discussion}

The large estimated response of the inflation rate to the decision to disinflate is driven by the success of the Volcker disinflation. Following the 1955, 1968, 1978, and 1988 decisions, forecast errors for inflation were positive or mixed. The 1974 episode was a temporary success, but inflation reasserted itself even before the second round of OPEC price increases. Perhaps it should not be surprising that the Volcker episode looks uniquely successful. Figure 1a shows how inflation continued to rise after each disinflation, even if there was a temporary retreat. Moreover, 
had the previous episodes been successful, the conditions that fostered the Volcker change in policy would not have been present. These results do not necessarily imply, however, that the future rate of inflation is not a primary variable of concern in motivating the Fed to disinflate. The Fed could act in the hope of having a success along the lines that Volcker did, even if in most cases these hopes are not realized. This issue of how the Fed reacts to inflation is addressed in the next section.

\section{CAUSE}

This section attempts to model the decision of the Fed to disinflate. In it I first calculate measures of the costs and benefits of the decision to disinflate. The estimates of the previous section are inputs into these calculations. I then estimate a discrete-choice model of the decision to disinflate based on these measures of costs and benefits.

The structure of the model is as follows. Let $\mathrm{R}_{\mathrm{t}}$ be the Fed's intolerance of inflation. This is an unobserved, continuous variable. When it exceeds a threshold (normalized to be zero), the Fed decides it is worthwhile to subject the economy to a 
disinflation. The structure of the econometric specification parallels that of the discrete-choice literature. The latent intolerance to inflation is modelled as a linear function of observables, $\mathrm{X}_{\mathbf{i}}$ :

$$
\mathrm{R}_{\mathrm{t}}^{*}=\mathrm{X}_{\mathrm{t}} \beta+\nu_{\mathrm{t}}
$$

When the intolerance exceeds the threshold, the Fed decides to change policy. That is,

$$
\mathrm{R}_{\mathrm{t}}=1 \text { when } \mathrm{R}_{\mathrm{t}}^{*}>0 \text {. }
$$

In this section, I first consider the variables that determine the decision to disinflate $\left(\mathrm{X}_{\mathrm{f}}\right)$. Then I use those variables to estimate the discrete-choice model.

\subsection{Variables Determining the Decision to Disinflate}

This section of the paper develops variables that are meant to explain the Fed's decision to disinflate. The obvious candidates 
are measures relating to unemployment (the cost of disinflation) and inflation (the potential benefit). In periods of high inflation, the Fed should be more likely to be contemplating a disinflation. In periods of high expected unemployment, the cost of disinflating is higher, so the Fed is less likely to make the economy suffer from a disinflation.

One approach would be to make the determining variables $\mathrm{X}_{\mathrm{t}}$ simply lags of the unemployment and inflation. But such a model would be misspecified on several grounds. First, presumably what the Fed is contemplating is the impact of its decision on future economic outcomes. Hence, the variables should be forward looking, although they should not use future information.

Second, inflation and unemployment are inertial. The quarter after a decision to disinflate, they will be about the same as they were when the decision was made. If the $X_{1}$ were based on the current values of unemployment and inflation, equations 2 and 3 would continue to predict changes in policy even after they had taken place. To avoid this misspecification, the variables $X_{1}$ must ratchet as a consequence of previous decision to disinflate. Again, this can be accomplished by making them forward looking. 
Forecasts of unemployment and inflation can react instantaneously even if the actual variables are sluggish.

Several other considerations about the specification of $\mathrm{X}_{\mathbf{1}}$ are driven by the fact that there are only a few episodes of policy change. The list of variables must be short. With an unparsimonious specification and only six disinflations in the sample, it would be very easy to overfit the model. Moreover, again because of the small number of episodes, there is little scope to let the data guide the choice of variables without running the risk that all fit is spurious.

With these considerations in mind, I use the following two measures as determinants of Federal Reserve decisions to disinflate. They are the expected present discounted value of the level of inflation and the expected present discounted value of unemployment.

These variables capture what one hopes are the central concerns of the Fed when it contemplates a change in aggregate policy. They are forward looking but based on current information and they summarize parsimoniously the current outlook conditional on whether or not a disinflation has recently occurred. Moreover, 
they are highly correlated with other variables that might be considered as candidates for driving the Fed's decision. In Section 2.2.2, I discuss the robustness of the posited measures to various changes in the specification.

These variables are calculated using the estimates developed in Section 1 of the paper. The relevant variables are forecast into the indefinite future for each point in the sample. The summary measures are calculated based on these forecasts. I then calculate their expected present discounted value using a 2 percent per quarter discount rate. The robustness of the measures to the discount rate is also considered below.

Note that the present value of the inflation rate might be a key determinant of the decision to disinflate despite the limited effect of the disinflations on inflation in most episodes. The Fed might react to the inflation rate even if it turns out it does not, in practice, succeed in changing it. 


\subsection{Variables Determining the Decision to Disinflate}

\subsubsection{Estimates of the Present Discounted Value of Forecasted}

Inflation and Unemployment

Figure 5 gives the estimated determinants of the decision to disinflate. The estimates are based on the multivariate system presented in Table $4 .{ }^{11}$ They are normalized by multiplying by one minus the discount rate so that the units are roughly at annual rate. In this section of the paper, only estimates based on the nonstationary inflation model will be presented. In the next subsection, I show that the present discounted value of forecast inflation is not that sensitive to the stationarity versus nonstationarity of inflation.

Figure 5a graphs the present discounted value of the forecasted inflation rate. Its low frequency movements track the actual inflation rate. The variable does ratchet down after Romer dates, but there are also fairly large changes not associated with Romer dates. Recall that the permanent effect of a Romer date is

${ }^{11}$ The equation for unemployment does not include the current change in inflation when it is used in this section. 
only 2-1/2 times the standard deviations of the innovation variance, so there can be expected to be large swings independent of the Romer dates.

The present discounted value of expected unemployment is given in Figure $5 b$. It falls steadily until a Romer date is encountered and then ratchets up once the disinflation occurs. Unlike inflation, the Romer dates appear to be the predominate factor in unemployment's business-cycle movements.

\subsubsection{Robustness}

As noted above, there is little scope for experimentation with the variables to be included in the model for estimating the probability of disinflation. Yet, since there is also little theoretical guidance as to the precise form of these variables. Therefore, one should be concerned whether the measures of the variables driving the Fed's decisions are robust to plausible perturbations of their specification. In this subsection, I consider how various alternative measures correlate with the ones used in the probit estimates. 
A plausible alternative measure of the inflation rate would be the long-run or asymptotic forecast of its level. ${ }^{12}$ This measure is very highly correlated with the one used in the present paper. Indeed, the correlation is 0.987 , so the measures are roughly interchangeable.

In Section 1, very different results were obtained for the stationary versus nonstationary specifications of the inflation rate. Two factors mitigate against there being much of a difference between these specifications for calculating present discounted values. First, the pattern of the change for the first four years is about the same. Second, discounting makes the differences in the distant years not matter much. Consequently, the correlation between the present discounted value of expected inflation for inflation-stationary and nonstationary is 0.986 for the discount rate of 0.02 per quarter. ${ }^{13}$

${ }^{12}$ Earlier drafts of this paper used this measure.

${ }^{13}$ This calculation should be taken with a grain of salt, however, because of the statistical insignificance of the Romer dates in the stationary specification of inflation. For this reason, I focus on the inflation nonstationary model. 
Finally, over plausible ranges of discount rates, the expected present discounted values remain highly coherent. This paper uses a 0.02 quarterly discount rate in calculating the expected present discounted value of inflation and unemployment. Compare these to those calculated with an extremely high discount rate, say 0.10 per quarter: The correlation of the inflation measure discounted with 0.02 versus 0.10 is 0.965 ; for unemployment, it is 0.964 .

\subsection{Estimated Probability of Disinflation}

The model in equations 2 and 3 are estimated using a probit specification of the disturbance. The explanatory variables are the lagged values of the expected present discounted value of inflation and unemployment. Model 1 uses just the inflation variable, model 2 uses just the unemployment variable, model 3 uses both. Expected inflation has the predicted impact on the decision to disinflate. Higher inflation raises the probability. The coefficient is strongly statistically significant. Likewise, expected unemployment also has the predicted impact. Lower unemployment raises the probability of disinflation, but the 
estimate is only marginally statistically significant. Including both variables does not alter much the magnitude of the estimated coefficients, indicating that they have an independent impact on the probability of a disinflation.

The estimated probit coefficients are difficult to interpret. Figures 6 through 8 give the implied probability of disinflation period-by-period for the three models. Except for the first disinflation, which this specification totally fails to predict, the probabilities have local peaks around the Romer dates. For the models including inflation, for just one date, the 1974 disinflation, does the probability of a disinflation exceed one half. Hence, the model does not do a good job of pinpointing the particular quarter when the disinflation will take place. But the probability is high over adjacent quarters, so the model does attribute a high probability to a disinflation taking place in the year that they occur. ${ }^{14}$

${ }^{14}$ Recall that the disinflations are rare. In a sample of 180 quarters, only seven occur. Hence, the unconditional probability of one occurring in any given quarter is less than 4 percent. The fitted probabilities should thus be judged against this baseline, not 
Given the low t-statistic of the unemployment variable in the estimates, it does not do a good job of tracking the decisions. Yet, Figure 7 illustrates the role it has in explaining disinflation. The probability slowly increases as unemployment falls prior to a Romer date. Since unemployment is so persistent, the variable does little to pinpoint that particular quarter of the disinflation. Hence, the low t-statistic. Yet, the integral of the probability over the quarters leading up to the disinflation would indicate the strong probability of a disinflation sometime during the period of low unemployment.

Consider the episodes in turn. As already has been noted, the 1955 episode is not explained by the model. Neither was unemployment expected to be particularly low nor was inflation particularly high.

The probability of disinflation grew steadily in the later 1960's until the 1969 episode. Comparing Figures 6 and 7, this

a baseline developed for cross-section studies where the number of zeros and ones in the explanatory variable are of the same order of magnitude. 
fitted probability is mainly associated with the unemployment variable.

The 1974 decision is the one most sharply predicted by the model. It combined the maximum expected inflation with fairly low expected unemployment (see Figure 7).

The next two best predicted decisions are the pair in the late 1970's. Inflation is the driving factor. Indeed, once unemployment is taken into account, the Volcker disinflation in 1979 has a lower fitted probability than when only inflation is included in the model (compare Figures 6 and 8 ). Why is the most successful disinflation not the most likely? It is precisely because expected unemployment was fairly high in late 1979, partially as a consequence of the failed disinflation of the previous year.

Finally, Romer and Romer (1992) have dated a seventh post-World War II disinflation in late 1988. The model concurs. It begins to predict a disinflation in 1987 based on the drift downward in the unemployment rate beginning in the mid-1980s. 
As with the 1969 episode, low unemployment rather than high inflation is the primary explanatory factor. ${ }^{15}$

Figure 9 presents estimates of a model that is intentionally misspecified. It uses estimates of the expected present discounted value of inflation and unemployment as explanatory variables in the probit that are based on a vector autoregression that do not include the Romer dates as explanatory variables. These results illustrate the importance of allowing the forcing variables to ratchet down after a Romer date. Because inflation and unemployment are persistent, the predictions using these forecasts tend to lag the events. The misspecified model continues to predict disinflations well after they have happened.

But perhaps more importantly, the results in Figure 9 provide some evidence that the results in the previous figures are not rigged by virtue of including the Romer date dummies as lagged variables in constructing the explanatory variables for the

${ }^{15}$ As a test of the specification and to further evaluate the new Romer date, I estimated the probit using data fit only through 1985 and then estimated the probabilities for the 1986-1992 period. They match quite closely those reported in Figure 8. 
probits. The fitted probabilities indeed do rise in the quarters before the Romer dates with much the same pattern as in Figure 8. An exception is the 1979 episode, which is better fit by the model reported in Figure 9. With this model, the cost of the disinflation is not being affected by the response of forecasted unemployment to the 1978 episode.

\section{SUMMARY}

This paper examines the Fed's decision to disinflate. It focusses on the role of pre-existing economic conditions in the decisions. It finds that these decisions are driven both by the prevailing unemployment and inflation rates. Even in periods of high inflation, the Fed will be relatively unwilling to disinflate if the rate of unemployment is otherwise expected to be high. Similarly, especially for the 1969 and 1988 episode, low unemployment rather than high inflation seems to explain the Fed's action.

In planning this paper, I expected estimating the inflation process to be merely a side issue. But the analysis of the inflation process proves very interesting in itself. While on average the "disinflations" do reduce the rate of inflation subsequently, this 
average result is driven almost entirely by the 1979 episode. This leads one to ask, what is the Fed accomplishing by putting the economy into a recession? Perhaps, it is responding to incipient inflation that is signalled by low unemployment. These could arise through nonlinearities in the Phillips curve not captured in simple specifications. Indeed, perhaps we do not see that region of the Phillips curve because the Fed never lets unemployment get so low. In any case, the economics profession's recent view that the Fed has had great success in reducing the rate of inflation, albeit with a temporary output loss, is largely colored by the achievement of the Volcker disinflation. Over the post-World War II period, the average disinflationary episode has done little to reduce the rate of inflation despite clear evidence that the changes in policy do cause unemployment to rise substantially. 


\section{REFERENCES}

Barsky, Robert B., 1987, "The Fisher Effect and the

Forecastablility and Persistence of Inflation," Journal of Monetary Economics 19, 3-24.

Dickey, David A. and Fuller, Wayne A., 1981, "Likelihood Ratio Statistics for Autoregressive Time Series with a Unit Root," Econometrica 49, 1057-72.

Feldstein, Martin S., 1979, "The Welfare Cost of Permanent Inflation and Optimal Short-Run Economic Policy," Journal of Political Economy 87, 749-768.

Romer, Christina D. and Romer, David H., 1989, "Does Monetary Policy Matter? A New Test in the Spirit of Friedman and Schwartz," NBER Macroeconomics Annual 4, 121-170. and , 1990, "New Evidence on the

Monetary Transmission Mechanism," Brookings Papers on Economic Activity 149-213. and , 1992, "Monetary Policy Matters," unpublished paper, University of California, Berkeley. 
Table 1

Persistence of Inflation: Various Samples since 1947

$\begin{array}{ll}\text { sample } & \begin{array}{l}\text { largest } \\ \text { autoregressive } \\ \text { root }\end{array}\end{array}$
of inflation ( 7 lags) and a constant (no trend). It reports the implied largest autoregressive root of the level of inflation and the Dickey-Fuller t-statistic for the null hypothesis that it is unity. 
Table 2

Estimated Response of Inflation and Unemployment Inflation Nonstationary, Univariate Estimates

\begin{tabular}{|c|c|c|c|c|c|}
\hline \multirow{2}{*}{$\begin{array}{l}\text { independent } \\
\text { variables } \\
\text { constant } \\
\Delta \pi\end{array}$} & lags & \multicolumn{2}{|c|}{$\Delta \pi$} & \multicolumn{2}{|c|}{$\mathrm{u}$} \\
\hline & & 0.40 & $(0.22)$ & -0.07 & $(0.03)$ \\
\hline$\Delta \pi$ & 1 & -0.63 & $(0.08)$ & & \\
\hline $\begin{array}{l}\Delta \pi \\
\Delta \pi\end{array}$ & 2 & -0.40 & $(0.10)$ & & \\
\hline$\Delta \pi$ & 3 & -0.04 & $(0.11)$ & & \\
\hline$\Delta \pi$ & 4 & -0.04 & $(0.10)$ & & \\
\hline$\Delta \pi$ & 5 & 0.01 & $(0.10)$ & & \\
\hline$\Delta \pi$ & 6 & 0.03 & $(0.10)$ & & \\
\hline$\Delta \pi$ & 7 & 0.08 & $(0.09)$ & & \\
\hline$\Delta \pi$ & 8 & -0.12 & $(0.07)$ & & \\
\hline u & 1 & & & 1.61 & $(0.08)$ \\
\hline $\mathrm{u}$ & 2 & & & -0.77 & $(0.15)$ \\
\hline $\mathrm{u}$ & 3 & & & 0.02 & $(0.16)$ \\
\hline $\mathbf{u}$ & 4 & & & -0.08 & $(0.16)$ \\
\hline $\mathbf{u}$ & 5 & & & 0.19 & $(0.16)$ \\
\hline $\mathbf{u}$ & 6 & & & 0.06 & $(0.16)$ \\
\hline $\mathbf{u}$ & 7 & & & -0.22 & $(0.15)$ \\
\hline $\mathrm{u}$ & 8 & & & 0.11 & $(0.08)$ \\
\hline $\mathbf{R}$ & 1 & 0.51 & $(0.71)$ & 0.07 & $(0.10)$ \\
\hline $\mathbf{R}$ & 2 & 0.11 & $(0.50)$ & 0.09 & $(0.07)$ \\
\hline $\mathrm{R}$ & 3 & -0.23 & $(0.41)$ & 0.11 & $(0.06)$ \\
\hline $\mathrm{R}$ & 4 & -0.50 & $(0.39)$ & 0.12 & $(0.06)$ \\
\hline $\mathbf{R}$ & 5 & -0.72 & $(0.39)$ & 0.13 & $(0.06)$ \\
\hline $\mathbf{R}$ & 6 & -0.89 & $(0.39)$ & 0.15 & $(0.06)$ \\
\hline $\mathbf{R}$ & 7 & -1.00 & $(0.38)$ & 0.15 & $(0.06)$ \\
\hline $\mathrm{R}$ & 8 & -1.07 & $(0.36)$ & 0.16 & $(0.06)$ \\
\hline $\mathrm{R}$ & 9 & -1.10 & $(0.35)$ & 0.16 & $(0.06)$ \\
\hline $\mathbf{R}$ & 10 & -1.09 & $(0.36)$ & 0.16 & $(0.06)$ \\
\hline $\mathbf{R}$ & 11 & -1.04 & $(0.38)$ & 0.15 & $(0.06)$ \\
\hline $\mathbf{R}$ & 12 & -0.96 & $(0.41)$ & 0.15 & $(0.07)$ \\
\hline $\mathrm{R}$ & 13 & -0.85 & $(0.44)$ & 0.13 & $(0.07)$ \\
\hline $\mathrm{R}$ & 14 & -0.72 & $(0.44)$ & 0.12 & $(0.07)$ \\
\hline $\mathbf{R}$ & 15 & -0.56 & $(0.41)$ & 0.09 & $(0.06)$ \\
\hline $\mathbf{R}$ & 16 & -0.39 & $(0.33)$ & 0.07 & $(0.05)$ \\
\hline S.E.E. & & 1.97 & & 0.30 & \\
\hline$\overline{\mathrm{R}}^{2}$ & & 0.33 & & 0.95 & \\
\hline $\begin{array}{l}F(3,140) \\
p-v a l u e\end{array}$ & & $\begin{array}{l}3.26 \\
0.02\end{array}$ & & $\begin{array}{l}3.09 \\
0.03\end{array}$ & \\
\hline
\end{tabular}

Note: Autoregression of change of inflation $(\Delta \pi)$ and detrended unemployment ( $u$ ) on own lags and Romer dates (R). Standard errors are in parenthesis. S.E.E. is standard error of regression. $\bar{R}^{2}$ is adjusted coefficient of determination. $F(3,140)$ and p-value are the F-statistic and rejection probability for the hypothesis the coefficients of $R$ are jointly zero. 
Table 3

Estimated Response of Inflation and Unemployment Inflation Stationary, Univariate Estimates

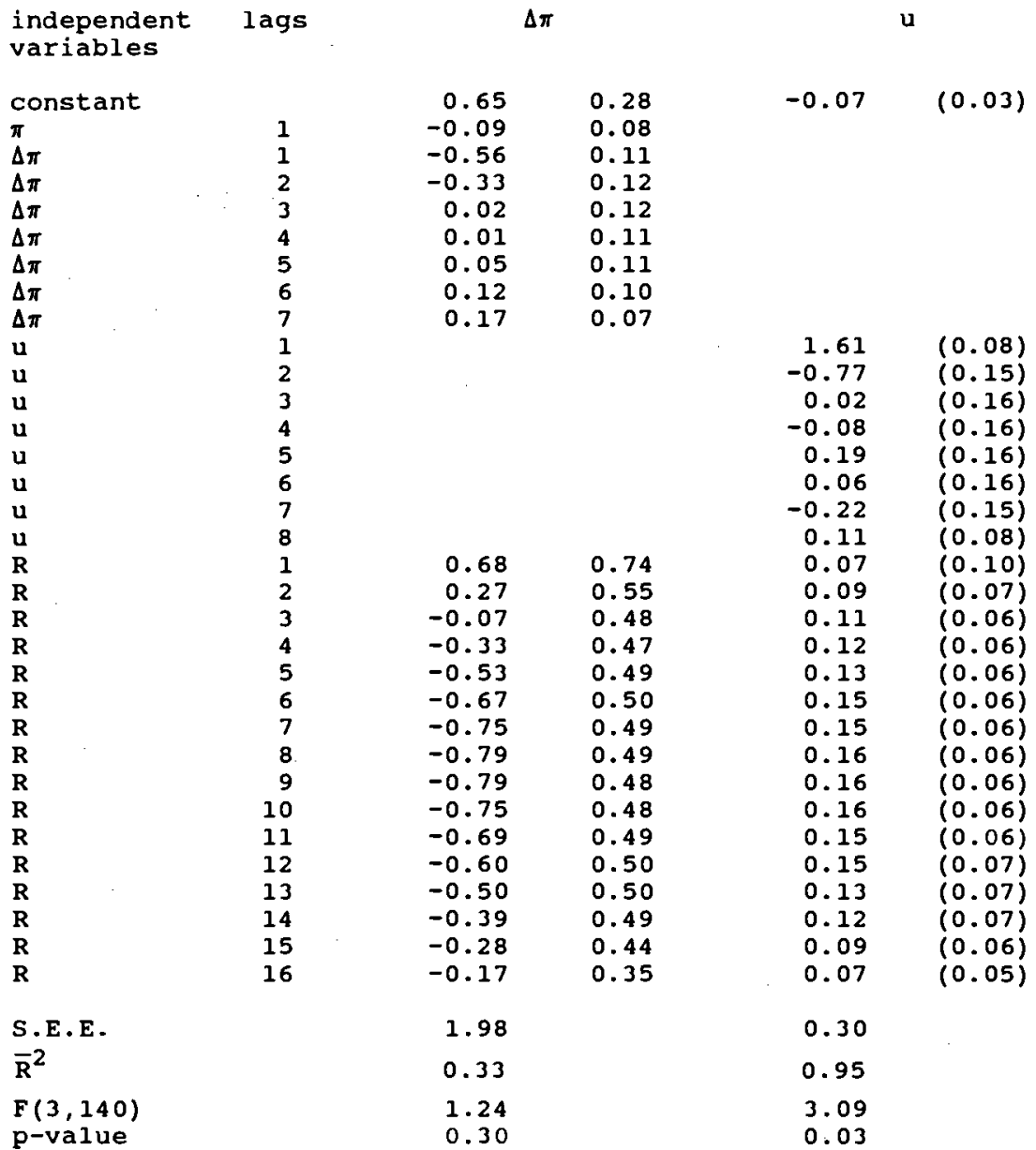

Note: Autoregression of change of inflation $(\Delta \pi)$ and detrended unemployment $(u)$ on own lags and Romer dates (R). Lagged level of inflation included to render inflation stationary.

See also note to Table 2 . 
Table 4

Estimated Response of Inflation and Unemployment Inflation Nonstationary, Multivariate Estimates

\begin{tabular}{|c|c|c|c|c|c|}
\hline $\begin{array}{l}\text { independent } \\
\text { variables }\end{array}$ & lags & \multicolumn{2}{|c|}{$\Delta \pi$} & \multicolumn{2}{|c|}{$\mathrm{u}$} \\
\hline constant & & 0.23 & $(0.21)$ & -0.06 & $(0.03)$ \\
\hline$\Delta \pi$ & 0 & & & -0.01 & $(0.01)$ \\
\hline$\Delta \pi$ & 1 & -0.73 & $(0.08)$ & 0.00 & $(0.02)$ \\
\hline$\Delta \pi$ & 2 & -0.47 & $(0.10)$ & 0.01 & $(0.02)$ \\
\hline$\Delta \pi$ & 3 & -0.10 & $(0.11)$ & -0.02 & $(0.02)$ \\
\hline$\Delta \pi$ & 4 & -0.06 & $(0.11)$ & 0.00 & $(0.02)$ \\
\hline$\Delta \pi$ & 5 & 0.05 & $(0.11)$ & 0.01 & $(0.02)$ \\
\hline$\Delta \pi$ & 6 & 0.16 & $(0.10)$ & 0.00 & $(0.02)$ \\
\hline$\Delta \pi$ & 7 & 0.19 & $(0.09)$ & 0.01 & $(0.01)$ \\
\hline$\Delta \pi$ & 8 & -0.03 & $(0.07)$ & 0.00 & $(0.01)$ \\
\hline $\mathbf{u}$ & 1 & -2.73 & $(0.50)$ & 1.60 & $(0.09)$ \\
\hline $\mathbf{u}$ & 2 & 3.42 & $(0.95)$ & -0.71 & $(0.16)$ \\
\hline $\mathbf{u}$ & 3 & -0.83 & $(1.02)$ & -0.07 & $(0.17)$ \\
\hline $\mathbf{u}$ & 4 & -1.13 & $(1.02)$ & -0.09 & $(0.17)$ \\
\hline $\mathbf{u}$ & 5 & 1.56 & $(1.01)$ & 0.34 & $(0.17)$ \\
\hline $\mathbf{u}$ & 6 & -1.22 & $(1.04)$ & -0.06 & $(0.17)$ \\
\hline $\mathbf{u}$ & 7 & 1.60 & $(0.95)$ & -0.19 & $(0.16)$ \\
\hline $\mathrm{u}$ & 8 & -0.88 & $(0.50)$ & 0.12 & $(0.08)$ \\
\hline $\mathbf{R}$ & 1 & 0.20 & $(0.65)$ & 0.06 & $(0.11)$ \\
\hline $\mathbf{R}$ & 2 & -0.01 & $(0.46)$ & 0.08 & $(0.08)$ \\
\hline $\mathbf{R}$ & 3 & -0.18 & $(0.38)$ & 0.09 & $(0.06)$ \\
\hline $\mathbf{R}$ & 4 & -0.31 & $(0.36)$ & 0.11 & $(0.06)$ \\
\hline $\mathbf{R}$ & 5 & -0.41 & $(0.37)$ & 0.12 & $(0.06)$ \\
\hline $\mathbf{R}$ & 6 & -0.48 & $(0.37)$ & 0.13 & $(0.06)$ \\
\hline $\mathbf{R}$ & 7 & -0.52 & $(0.37)$ & 0.14 & $(0.06)$ \\
\hline $\mathbf{R}$ & 8 & -0.53 & $(0.35)$ & 0.15 & $(0.06)$ \\
\hline $\mathbf{R}$ & 9 & -0.53 & $(0.35)$ & 0.15 & $(0.06)$ \\
\hline$R$ & 10 & -0.50 & $(0.36)$ & 0.15 & $(0.06)$ \\
\hline $\mathbf{R}$ & 11 & -0.46 & $(0.38)$ & 0.15 & $(0.06)$ \\
\hline $\mathbf{R}$ & 12 & -0.41 & $(0.40)$ & 0.14 & $(0.07)$ \\
\hline $\mathbf{R}$ & 13 & -0.35 & $(0.42)$ & 0.13 & $(0.07)$ \\
\hline $\mathbf{R}$ & 14 & -0.28 & $(0.42)$ & 0.12 & $(0.07)$ \\
\hline $\mathbf{R}$ & 15 & -0.20 & $(0.39)$ & 0.10 & $(0.06)$ \\
\hline $\mathrm{R}$ & 16 & -0.13 & $(0.32)$ & 0.07 & $(0.05)$ \\
\hline S.E.E. & & 1.78 & & 0.30 & \\
\hline$\overline{\mathrm{R}}^{2}$ & & 0.45 & & 0.95 & \\
\hline$F(3,140)$ & & 0.78 & & 2.59 & \\
\hline p-value & & 0.51 & & 0.06 & \\
\hline
\end{tabular}

Note: Vector autoregressions of change of inflation $(\Delta \pi)$ and detrended unemployment (u) on own lags and Romer dates (R). current $\Delta \pi$ included in equation for $u$ to triangularize the system.

See also note to Table 2 . 
Table 5

Estimated Response of Inflation and Unemployment Inflation stationary, Multivariate Estimates

\begin{tabular}{|c|c|c|c|c|c|}
\hline $\begin{array}{l}\text { independent } \\
\text { variables }\end{array}$ & lags & & & & \\
\hline constant & & 0.35 & $(0.26)$ & -0.08 & $(0.04)$ \\
\hline$\pi$ & 1 & -0.05 & $(0.07)$ & 0.01 & $(0.01)$ \\
\hline$\Delta \pi$ & 0 & & & -0.01 & $(0.01)$ \\
\hline$\Delta \pi$ & 1 & -0.69 & $(0.11)$ & -0.00 & $(0.02)$ \\
\hline$\Delta \pi$ & 2 & -0.43 & $(0.12)$ & 0.00 & $(0.02)$ \\
\hline$\Delta \pi$ & 3 & -0.06 & $(0.13)$ & -0.02 & $(0.02)$ \\
\hline$\Delta \pi$ & 4 & -0.03 & $(0.12)$ & 0.00 & $(0.02)$ \\
\hline$\Delta \pi$ & 5 & 0.08 & $(0.11)$ & 0.01 & $(0.02)$ \\
\hline$\Delta \pi$ & 6 & 0.19 & $(0.10)$ & -0.00 & $(0.02)$ \\
\hline$\Delta \pi$ & 7 & 0.21 & $(0.07)$ & 0.01 & $(0.01)$ \\
\hline $\mathbf{u}$ & 1 & -2.73 & $(0.50)$ & 1.60 & $(0.09)$ \\
\hline $\mathbf{u}$ & 2 & 3.41 & $(0.94)$ & -0.71 & $(0.16)$ \\
\hline $\mathbf{u}$ & 3 & -0.81 & $(1.02)$ & -0.07 & $(0.17)$ \\
\hline $\mathbf{u}$ & 4 & -1.15 & $(1.02)$ & -0.08 & $(0.17)$ \\
\hline $\mathbf{u}$ & 5 & 1.57 & $(1.01)$ & 0.34 & $(0.17)$ \\
\hline $\mathbf{u}$ & 6 & -1.18 & $(1.04)$ & -0.06 & $(0.17)$ \\
\hline $\mathbf{u}$ & 7 & 1.57 & $(0.95)$ & -0.19 & $(0.16)$ \\
\hline $\mathbf{u}$ & 8 & -0.87 & $(0.49)$ & 0.12 & $(0.08)$ \\
\hline $\mathbf{R}$ & 1 & 0.32 & $(0.68)$ & 0.04 & $(0.11)$ \\
\hline $\mathbf{R}$ & 2 & 0.12 & $(0.51)$ & 0.06 & $(0.09)$ \\
\hline $\mathbf{R}$ & 3 & -0.03 & $(0.45)$ & 0.07 & $(0.08)$ \\
\hline $\mathbf{R}$ & 4 & -0.15 & $(0.45)$ & 0.09 & $(0.08)$ \\
\hline $\mathbf{R}$ & 5 & -0.24 & $(0.47)$ & 0.10 & $(0.08)$ \\
\hline $\mathbf{R}$ & 6 & -0.30 & $(0.48)$ & 0.11 & $(0.08)$ \\
\hline $\mathbf{R}$ & 7 & -0.33 & $(0.47)$ & 0.12 & $(0.08)$ \\
\hline $\mathbf{R}$ & 8 & -0.34 & $(0.47)$ & 0.12 & $(0.08)$ \\
\hline $\mathbf{R}$ & 9 & -0.33 & $(0.46)$ & 0.13 & $(0.08)$ \\
\hline $\mathbf{R}$ & 10 & -0.31 & $(0.46)$ & 0.13 & $(0.08)$ \\
\hline $\mathbf{R}$ & 11 & -0.27 & $(0.46)$ & 0.13 & $(0.08)$ \\
\hline $\mathbf{R}$ & 12 & -0.23 & $(0.47)$ & 0.12 & $(0.08)$ \\
\hline $\mathbf{R}$ & 13 & -0.18 & $(0.47)$ & 0.11 & $(0.08)$ \\
\hline $\mathbf{R}$ & 14 & -0.13 & $(0.46)$ & 0.10 & $(0.08)$ \\
\hline $\mathbf{R}$ & 15 & -0.09 & $(0.41)$ & 0.08 & $(0.07)$ \\
\hline $\mathbf{R}$ & 16 & -0.05 & $(0.33)$ & 0.06 & $(0.05)$ \\
\hline S.E.E. & & 1.78 & & 0.29 & \\
\hline$\overline{\mathbf{R}}^{2}$ & & 0.45 & & 0.95 & \\
\hline $\begin{array}{l}F(3,140) \\
p \text {-value }\end{array}$ & & $\begin{array}{l}0.27 \\
0.85\end{array}$ & & $\begin{array}{l}0.97 \\
0.40\end{array}$ & \\
\hline
\end{tabular}

Note: Vector autoregressions of change of inflation ( $\Delta \pi$ ) and detrended unemployment (u) on own lags and Romer dates (R). Lagged level of inflation included to render inflation stationary: Current $\Delta \pi$ included in equation for $u$ to triangularize the system.

see also note to Table 2 . 
Table 6

Decision to Disinflate: Probit Estimates

$\begin{array}{lccc} & \text { Model } 1 & \text { Model } 2 & \text { Model } 3 \\ \text { constant } & -4.04 & -1.92 & -4.25 \\ & (0.82) & (0.23) & (0.89) \\ \text { PDV inflation } & 0.35 & & 0.36 \\ & (0.11) & & (0.12) \\ \text { PDV unemployment } & & -1.62 & (0.99) \\ & & (0.92) & -18.29\end{array}$

Probit estimates using values of the expected present discounted value (PDV) of inflation and unemployment as explanatory variables for Fed decisions to disinflate. See text for details. Standard errors in parentheses. 
Figure 1. Inflation, Unemployment and the Decision to Disinflate (a) InPlation Rate (4-quarter)

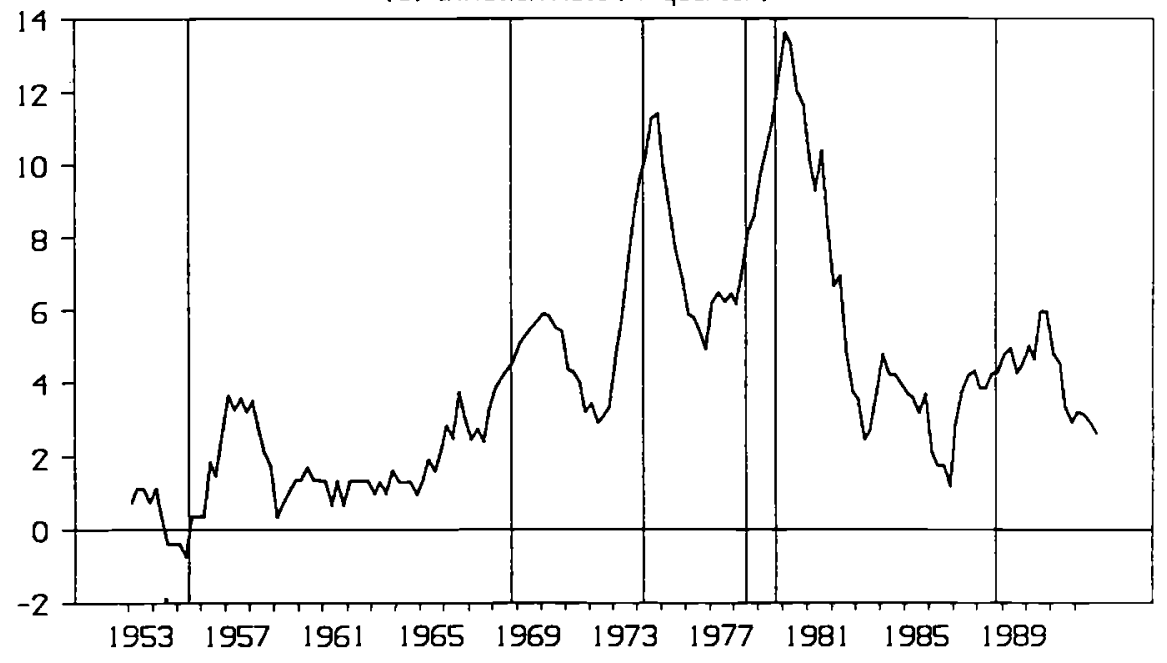

(b) Unemployment Rate

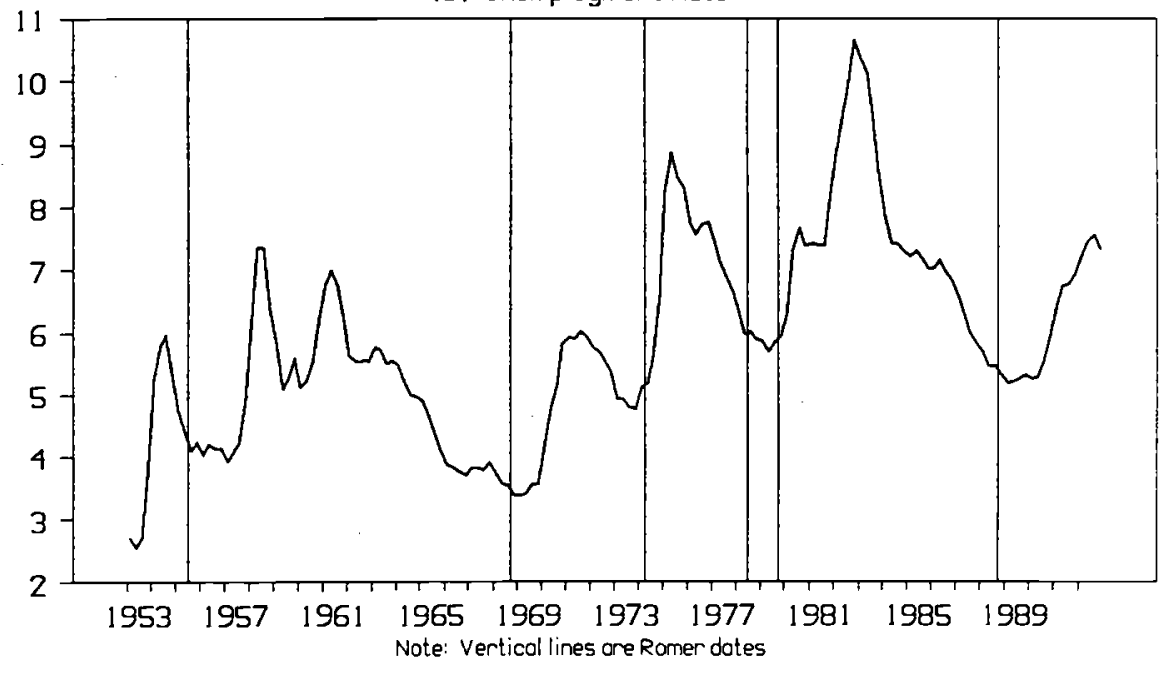


Figure 2. Response of Unemployment and Inflation to a Romer Date

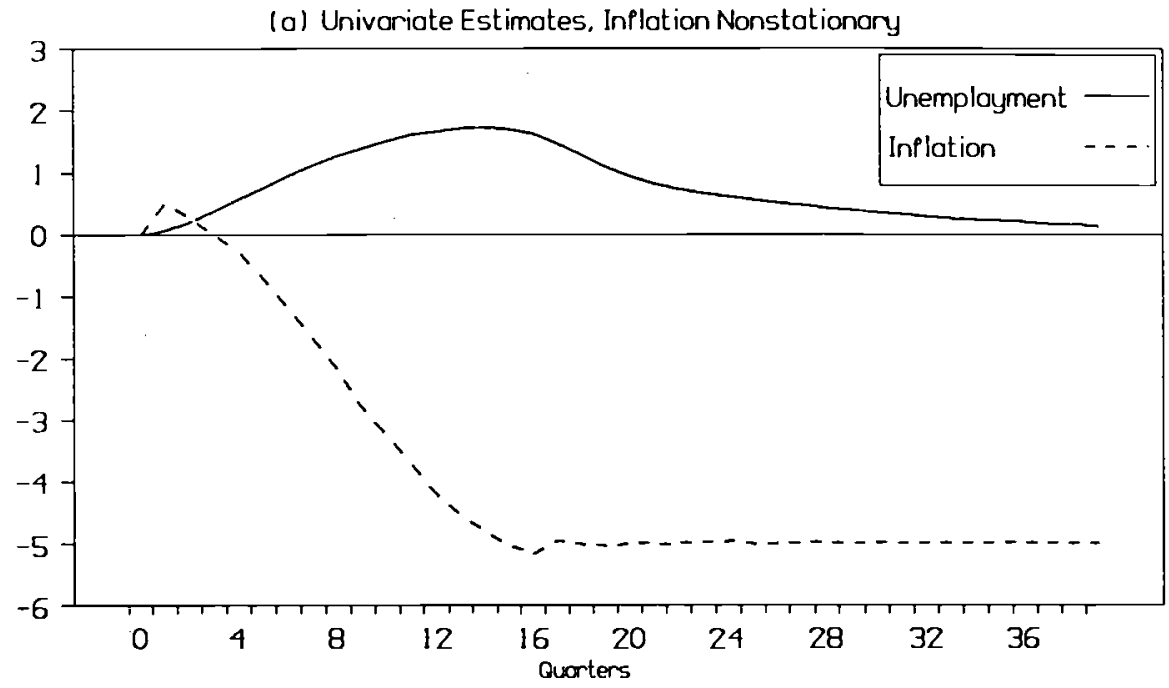

(b) Multivariate Estimates, Inflation Nonstationary

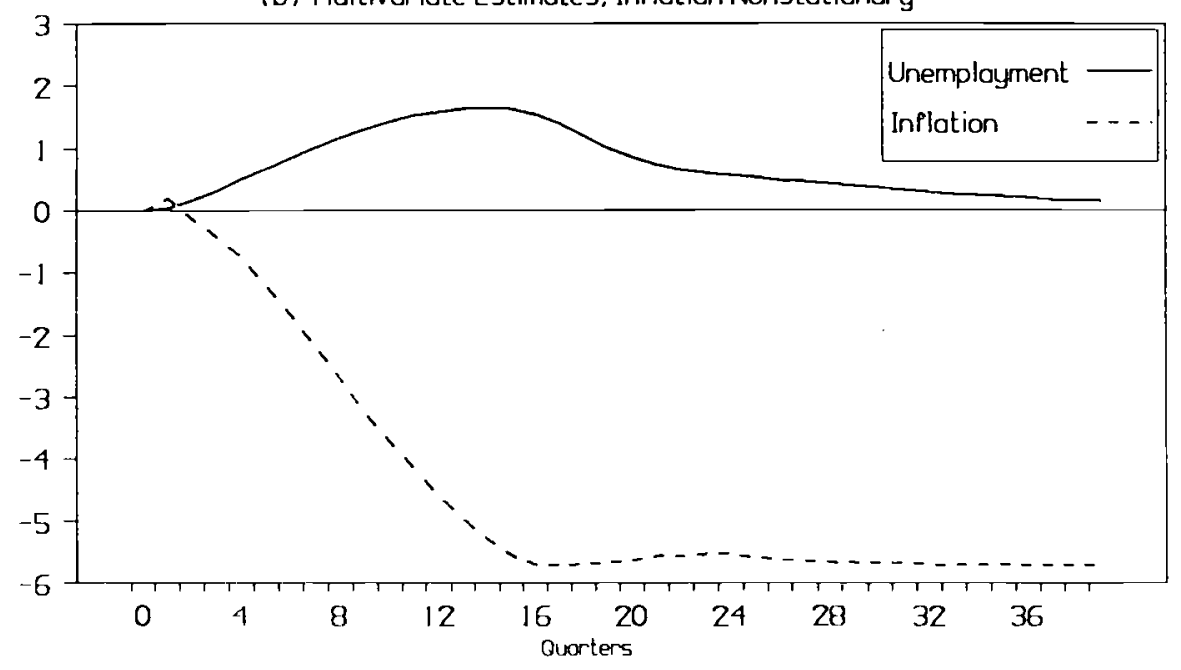


Figure 3. Response of Unemployment and Inflotion to a Romer Dote

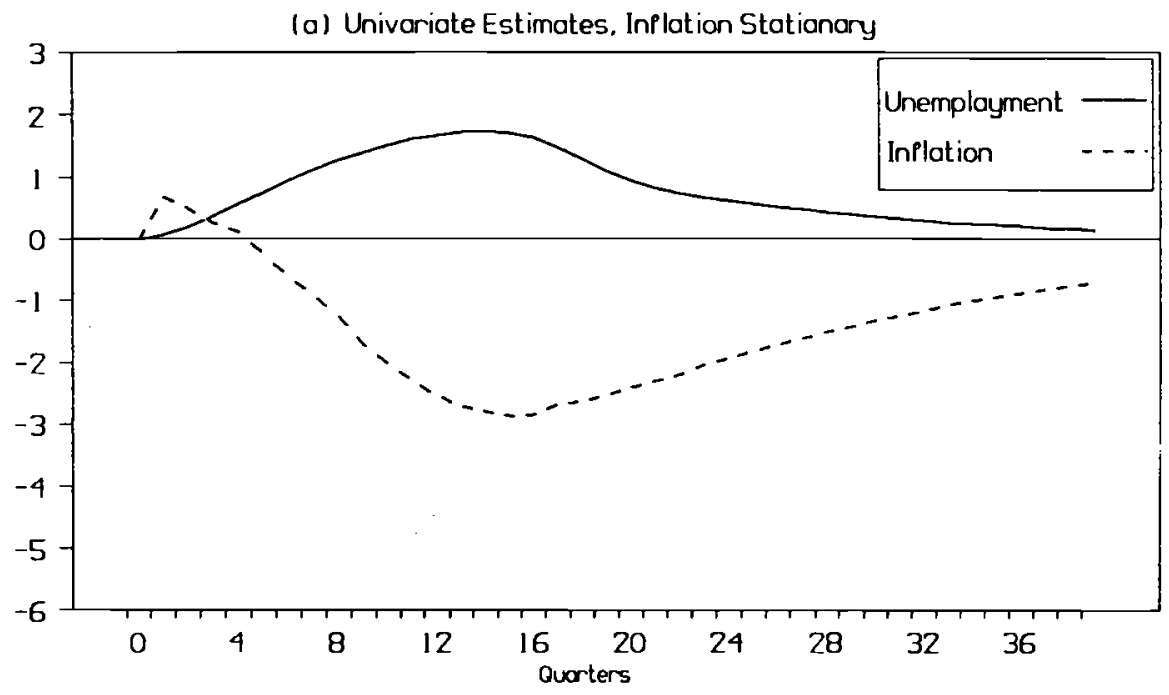

(b) Multivariate Estimates, Inflation Stationary

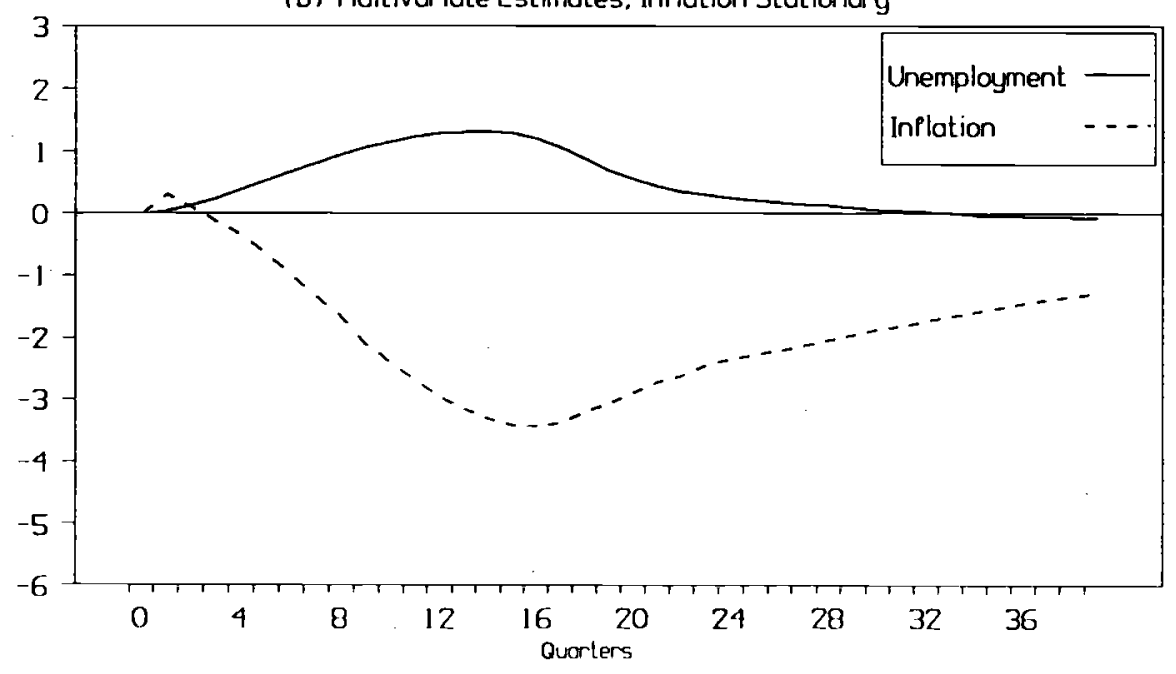


Figure 4. Farecost Error for Inflation Following Decisions to Disinflate (a) September 1955

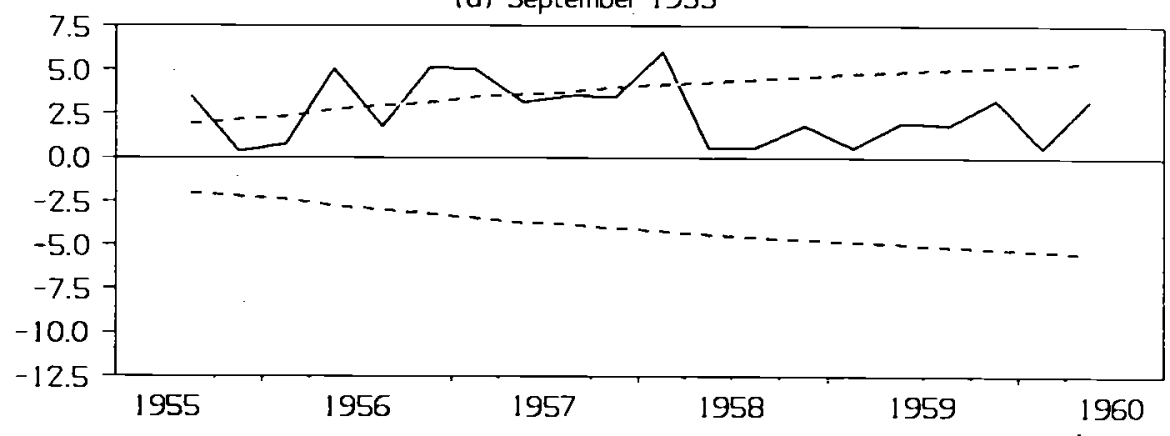

(b) December 1968

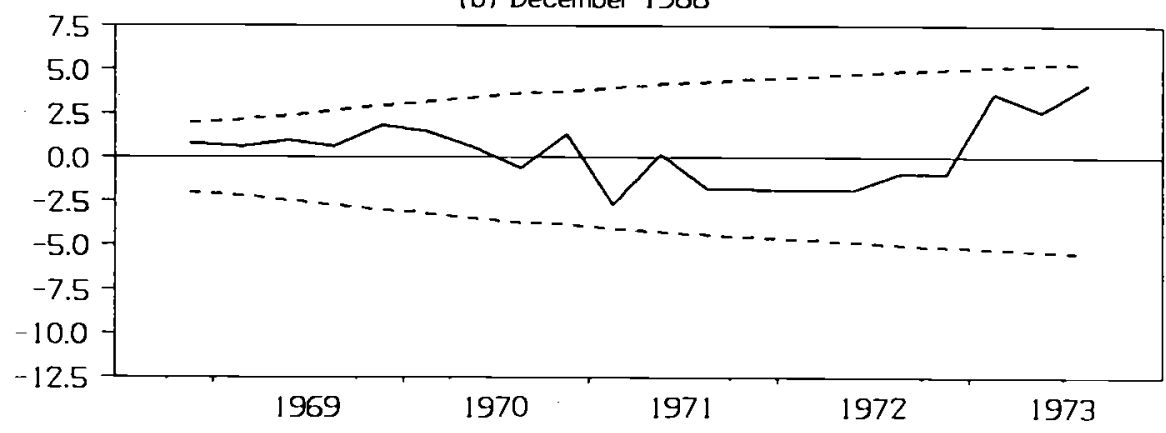

(c) April 1974

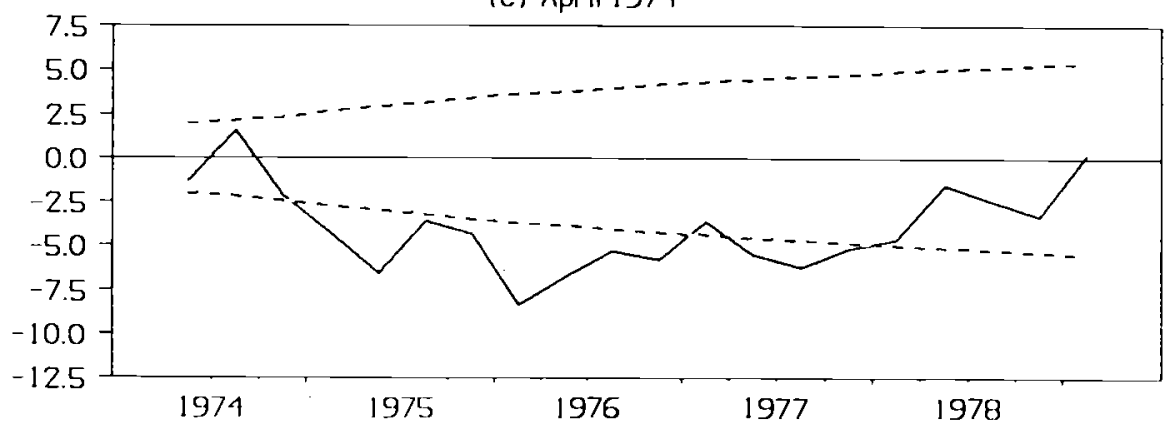


Figure 4. (continued)

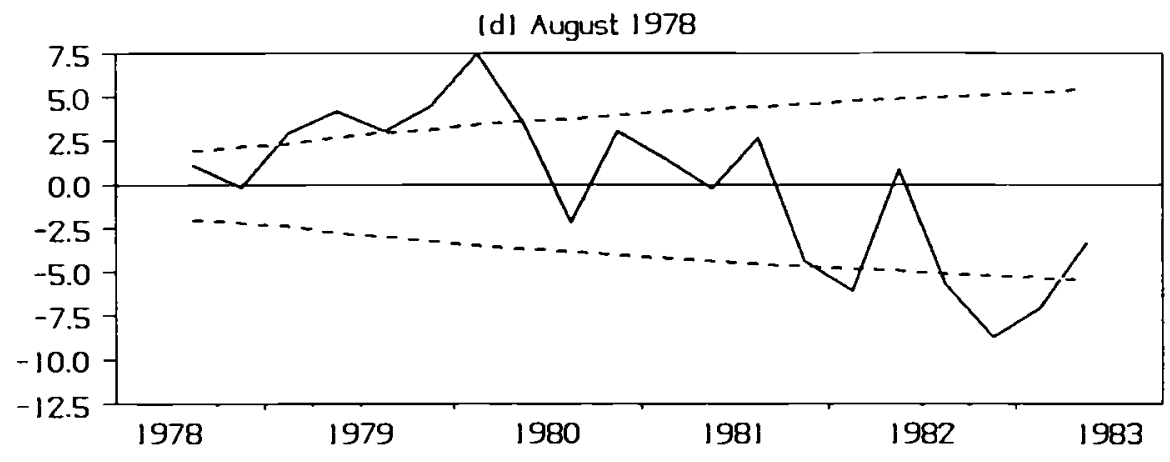

(e) October 1979
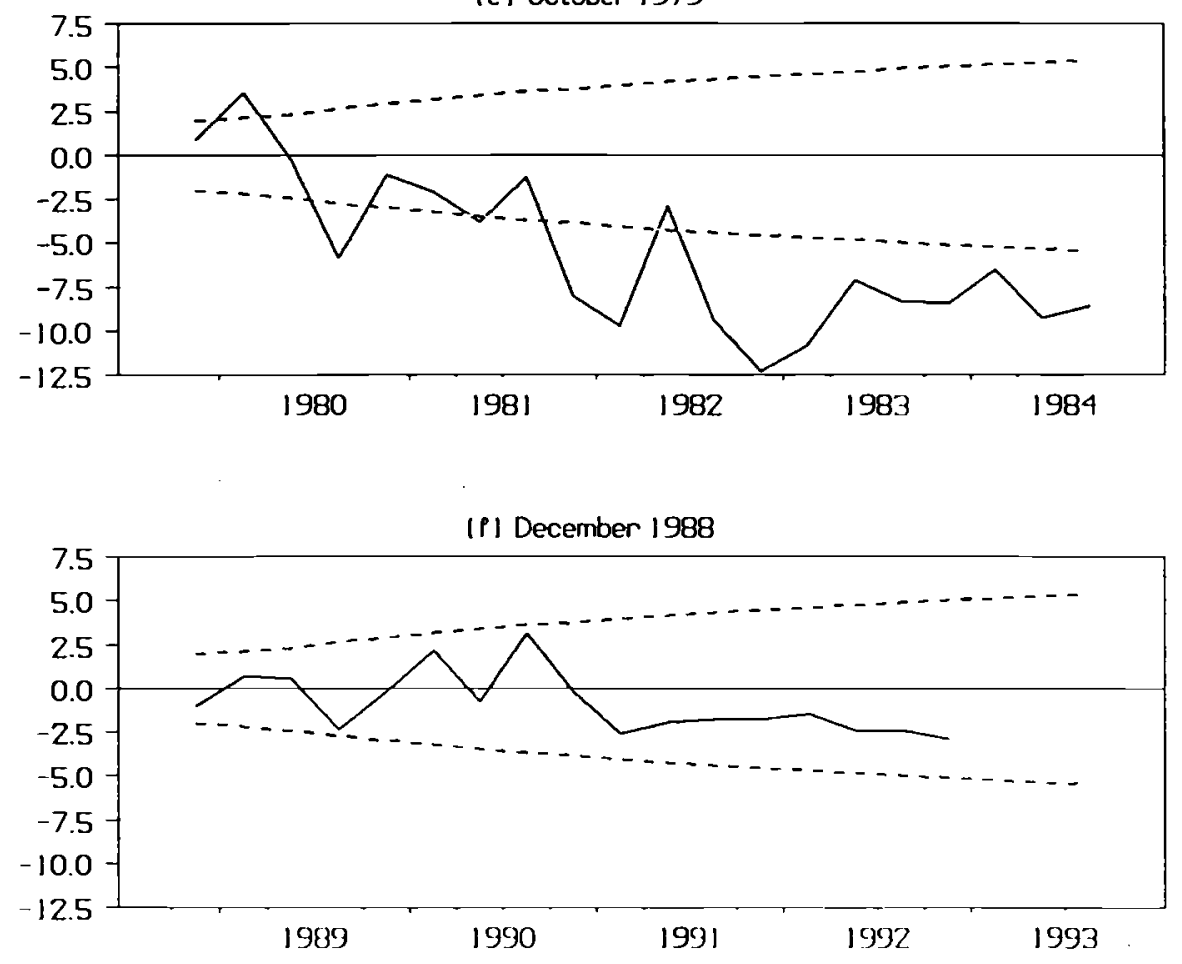
Figure 5. Variables Determining Decision of Fed to Disinflate (a) Present Discounted Value of Expected InPlation

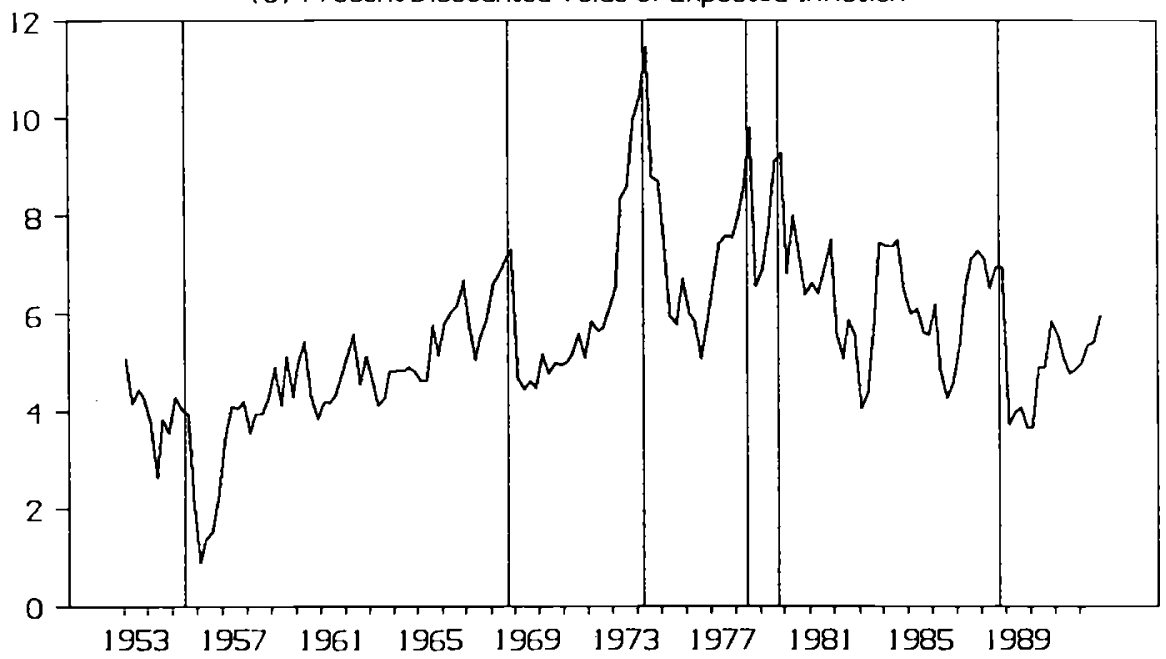

(b) Present Discounted Volue of Expected Unemployment

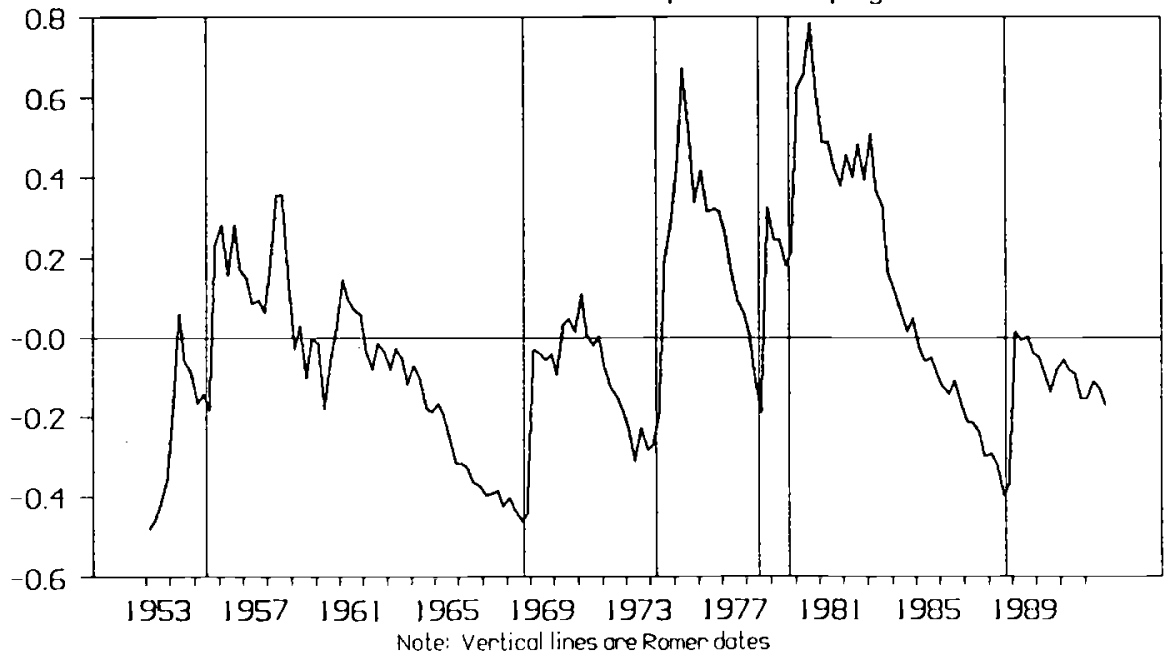


Figure 6. Estimated Probability of Disinflotion

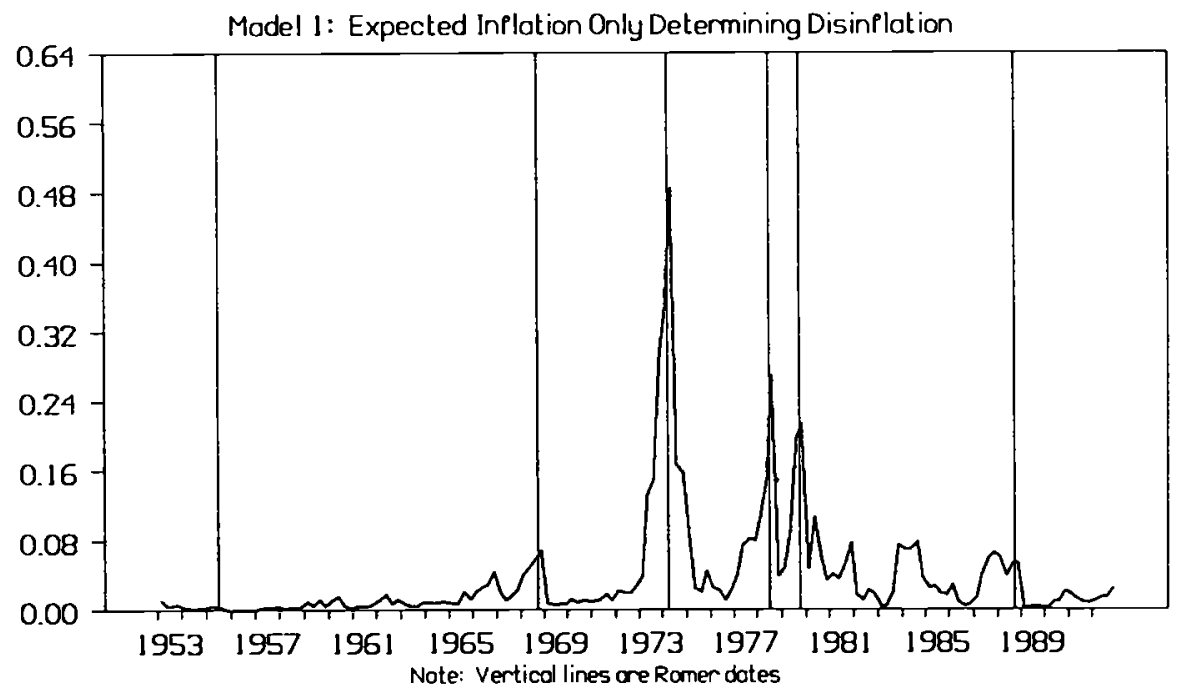


Figure 7. Estimated Probability of Disinflation

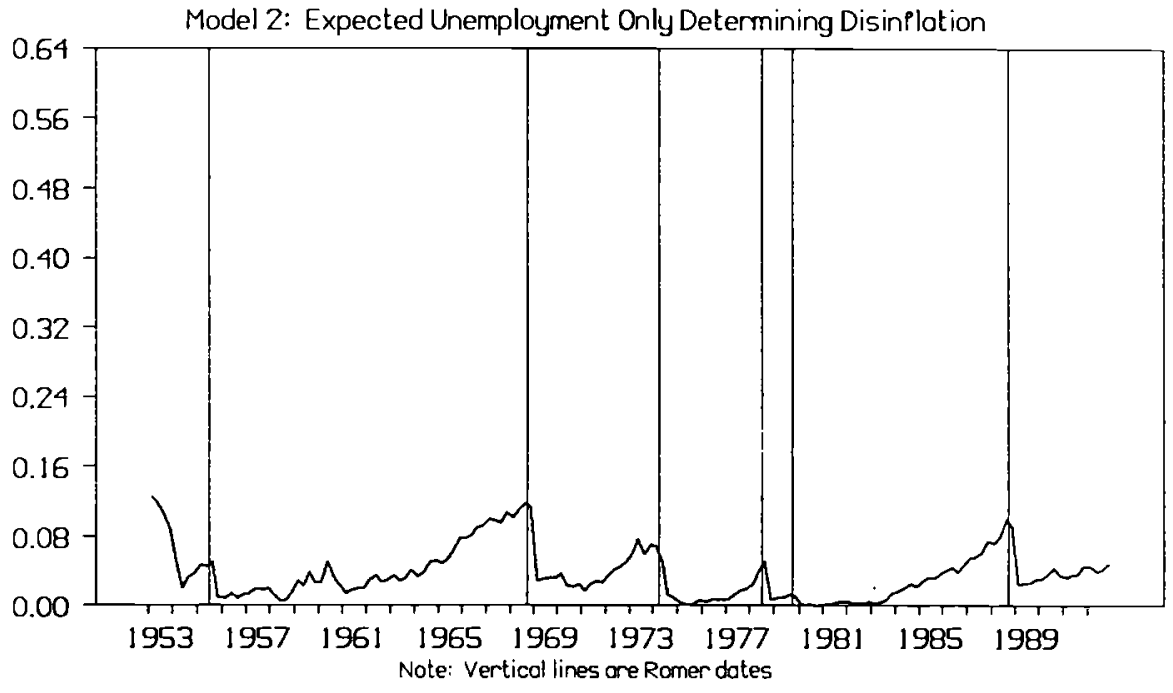


Figure 8. Estimated Probability of Disinflation

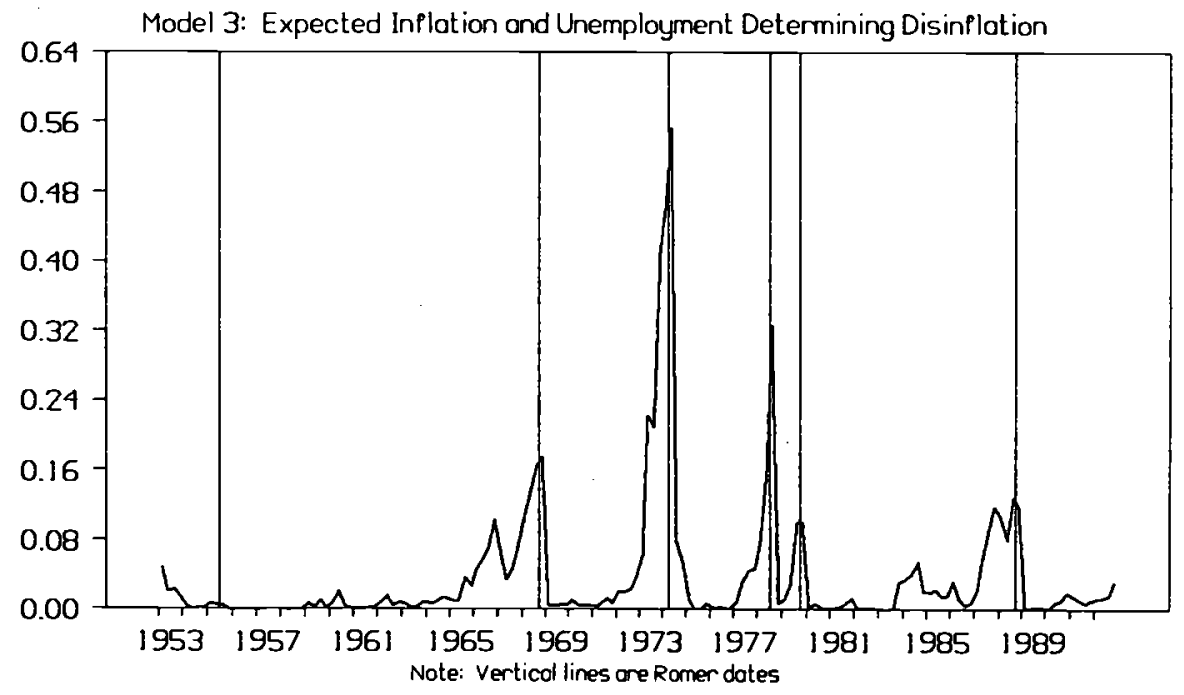


Figure 9. Estimated Probability of Disinflation MisspeciPied Model: No Ratchet

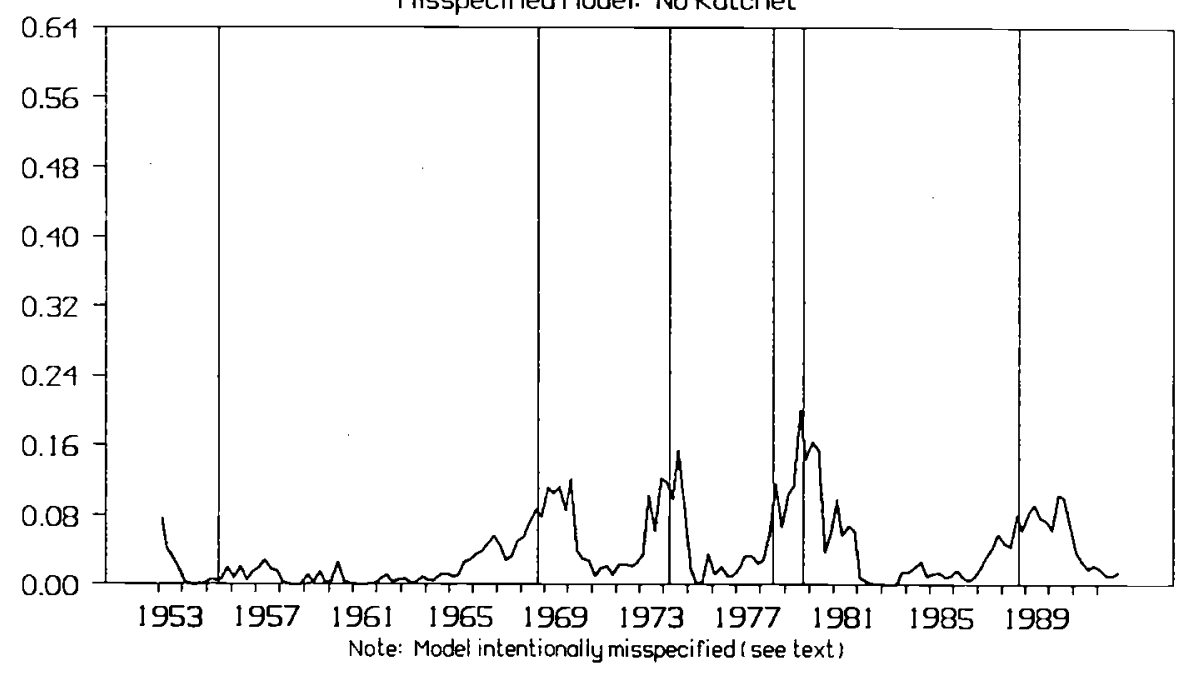

